\title{
“O FUTURO ESTAVA LÁ": \\ O SURGIMENTO DO GRUPO ESCOLAR ANTÔNIO JOÃO RIBEIRO DE ITAPORÃ NA REGIÃO DE DOURADOS (1953-1970)
}

\author{
"The future was there": the emergence of the Antonio João Ribeiro of Itaporã in the \\ Dourados region (1953-1970)
}

“El futuro estava lá": el surgimiento del grupo escolar Antônio João Ribeiro de Itaporã en la región de dourados (1953-1970)

\author{
Claudiani Rodelini ${ }^{1}$ \\ Maria do Carmo Brazil ${ }^{2}$
}

\begin{abstract}
Resumo
O presente artigo tem o propósito de comunicar os resultados da investigação realizados acerca do Grupo Escolar Antônio João Ribeiro de Itaporã, focada nas condições políticas e sociais decisivas para sua implantação, nas suas formas de funcionamento, bem como suas práticas cotidianas e dos distintos agentes sociais da comunidade, entre os anos de1953 a 1974. O ano de 1953 refere-se ao ano de criação do município de Itaporã, por meio da Lei Municipal 659, de 10 de dezembro de 1953. O ano de 1974 liga-se à data em que a referida instituição o definitivamente elevou-se a escola de $1^{\circ} \mathrm{Grau}$ - passando a denominar-se Escola Antônio João Ribeiro. A pesquisa ancorou-se teoricamente na perspectiva teórica da Nova História Cultural (NHC), com distinção para os referenciais de Roger Chartier (2002) e Certeau (1982), Buscamos dados nos núcleos de documentação (CDR/MS e NDHIR/MT), onde estão reunidos os documentos oficiais, relatórios oriundos da Diretoria Geral da Instrução Pública de Mato Grosso (1950-1970), jornais da época , com destaque para o Jornal "O Progresso". Recorri também aos materiais reunidos no arquivo da escola, livros de registros, livros ata e nos acervos privados, fotos, certificados de conclusão de curso e diplomas, fornecidos por alguns moradores da cidade de Itaporã-MS. Também foram incorporados ao trabalho depoimentos orais fornecidos por sujeitos que vivenciaram o cotidiano do Grupo Escolar Antônio João Ribeiro no período escolhido para o estudo. Em síntese foi possível observar que em Mato Grosso havia uma preocupação, por parte dos governantes, de se criar novas escolas e instruir a população, sendo o Grupo Escolar um dos principais meios de se difundir os projetos políticos que levariam ao progresso e à modernidade da nação.
\end{abstract}

PALAVRAS-CHAVE: Escola e Missão Franciscana. Escolarização Rural. CAND e a Escola.

\begin{abstract}
The purpose of this article is to communicate the results of the research carried out about the Antônio João Ribeiro de Itaporã School Group, focused on the political and social conditions that are decisive for its implementation, in its ways of functioning, as well as its daily practices and the

\footnotetext{
${ }^{1}$ Professora de História da SED/MS. Mestre em Educação UFGD, linha de pesquisa: História da Educação, Memória e Sociedade e membro do grupo de pesquisa GEPHEMS. Email: claudiani_rodelini@ hotmail.com ${ }^{2}$ Professora Titular em História do Brasil da Universidade Federal da Grande Dourados. Docente da Faculdade de Educação. Faz parte do corpo docente permanente do Programa de Pós-Graduação em Educação e do Programa de Pós-Graduação em História da UFGD. Email: mariabrazil@ufgd.edu.br
} 
different social agents of the community, between the years of 1953 to 1974 . The year of 1953 refers to the year of creation of the municipality of Itaporã, through Municipal Law 659, of December 10, 1953. The year of 1974 is related to the date in that the mentioned institution definitively elevated itself to the school of $1^{\circ}$ Degree - happening to denominate School Antônio João Ribeiro. The research was theoretically based on the theoretical perspective of the New Cultural History (NHC), with distinction for the references of Roger Chartier (2002) and Certeau (1982). We searched data in the documentation centers (CDR / MS and NDHIR / MT), where the official documents are gathered, reports coming from the General Direction of the Public Instruction of Mato Grosso (1950-1970), newspapers of the time, with highlight to the Journal "The Progress". I also looked at the materials collected in the school archive, records books, books and private collections, photos, certificates of completion and diplomas, provided by some residents of the city of Itaporã-MS. Also included in the work were oral testimonies provided by subjects who lived the daily life of the School Group Antônio João Ribeiro in the period chosen for the study. In summary, it was possible to observe that in Mato Grosso there was a concern, on the part of the governors, to create new schools and educate the population, the School Group being one of the main means of spreading the political projects that would lead to the progress and modernity of the nation.

KEYWORDS: Franciscan School and Mission. Rural Schooling. CAND and school

\section{Resumen}

El presente artículo tiene el propósito de comunicar los resultados de la investigación realizados sobre el Grupo Escolar Antônio João Ribeiro de Itaporá, enfocada en las condiciones políticas y sociales decisivas para su implantación, en sus formas de funcionamiento, así como sus prácticas cotidianas y de los distintos agentes sociales de la comunidad, entre los años de 1953 a 1974. El año 1953 se refiere al año de creación del municipio de Itaporã, por medio de la Ley Municipal 659, del 10 de diciembre de 1953. El año 1974 se conecta a la fecha en que la referida institución lo definitivamente se elevó a la escuela de $1^{\circ}$ Grado - pasando a denominarse Escuela Antônio João Ribeiro. La investigación se ancló teóricamente en la perspectiva teórica de la Nueva Historia Cultural (NHC), con distinción para los referentes de Roger Chartier (2002) y Certeau (1982), Buscamos datos en los núcleos de documentación (CDR / MS y NDHIR / MT), donde se reúnen los documentos oficiales, informes provenientes de la Dirección General de la Instrucción Pública de Mato Grosso (1950-1970), diarios de la época, con destaque para el periódico "El Progreso". También recurrí a los materiales reunidos en el archivo de la escuela, libros de registros, libros actas y en los acervos privados, fotos, certificados de conclusión de curso y diplomas, proporcionados por algunos residentes de la ciudad de Itaporá-MS. También fueron incorporados al trabajo testimonios orales proporcionados por sujetos que vivenciaron el cotidiano del Grupo Escolar Antônio João Ribeiro en el período escogido para el estudio. En síntesis fue posible observar que en Mato Grosso había una preocupación por parte de los gobernantes de crear nuevas escuelas e instruir a la población, siendo el Grupo Escolar uno de los principales medios de difundir los proyectos políticos que llevarían al progreso ya la modernidad nación.

PALABRAS CLAVE: Escuela y Misión Franciscana. Escolarización rural. CAND y escuela.

\section{INTRODUÇÃO}

Esta abordagem vincula-se ao campo da História da Educação, em especifico volta-se para análises sobre a História das Instituições Educativas (HIE), envolvendo o período de 1953 a 1974, com objetivo de tecer considerações sobre o processo de 
instalação da escola primária de Itaporã, no sul do antigo Mato Grosso, com destaque para as condições históricas que permitiram o surgimento do Grupo Escolar Antônio João Ribeiro, bem como a importância desta instituição para o município de Itaporã (MT). Para tanto, procuramos discutir a escola no âmbito do processo de implantação dos Grupos Escolares nas áreas internas do Brasil.

A delimitação do período de abordagem, entre os anos de 1953 a 1974, justifica-se pela criação do município de Itaporã, por meio da Lei Municipal 659, de 10 de dezembro de 1953, ratificada pela Lei $n^{\circ} 370$, de 31 de junho de 1954, a qual garantiu a emancipação política do município. O ano de 1974 refere-se à data em que o Grupo Escolar elevou-se a escola de $1^{\circ}$ Grau, passando a denominar-se Escola Antônio João Ribeiro, como cumprimento da Lei 5692/71, que determinou a extinção dos grupos escolares no Brasil.

Segundo a tradição oral ou a cultura material e tradição dos moradores itaporaenses, as famílias de migrantes originárias de São Paulo e do Paraná, os quais alcançaram Itaporã no ano de 1944. Estes agentes, ao assentarem-se na região, se mobilizaram para que seus filhos pudessem obter condições materiais de escolarização. Ressaltamos aqui o exemplo da senhora Olímpia Moura que, em 1945, recém-chegada à localidade, se dispôs a ministrar aulas para filhos de migrantes ligados às atividades ali desenvolvidas. Surgia, assim, a primeira escola na localidade urbana, a qual funcionava na residência da própria professora, até o ano de 1952. Dois anos mais tarde, a escola foi elevada à modalidade de Escola Reunida, pela Prefeitura de Dourados, com o nome Escolas Reunidas de Itaporã (Decreto Estadual 1.927/54). A referida escola permaneceu com esta modalidade de escola até 1955, quando foi transformada em "Grupo Escolar Antônio João Ribeiro" (GE) com base no Decreto Estadual de 2.197/55, permanecendo ativo até 1974. Ainda no ano de 1974, o GE foi elevado a Escola Estadual de Primeiro Grau Antônio João Ribeiro.

Este estudo versa sobre a origem e instalação da escola no período compreendido entre 1953 a 1974. Embora a Lei 5.692/71 tivesse passado a vigorar no ano de 1971, em Mato Grosso, a instituição manteve-se nos moldes de "Grupo Escolar" até o ano de 1974, ou seja, de forma singular, cada instituição escolar organizou seu processo de alteração de denominação ou nomenclatura junto à Secretaria de Estado de Educação e Cultura.

O cenário nacional em que se configura o tempo do Grupo Escolar Antônio João Ribeiro foi posterior ao Ato Institucional de número 5 (AI-5/ 1964-1985), o quinto de dezessete decretos implementados pela ditadura militar. Direta ou indiretamente, os sujeitos que se movimentavam no cenário itaporaense vivenciaram singularmente os anos da ditadura militar (1964-1985). Mato Grosso, mesmo distante das efervescências políticas ocorridas nos grandes centros urbanos (São Paulo e Rio de Janeiro), não esteve "à margem" da história brasileira.

O Grupo Escolar, como ocorreu em todos os estados brasileiros, reproduzia as práticas do governo militar, cumprindo as leis instituídas no período. A cobrança exagerada do uniforme, as atividades cívicas ufanistas, a inclusão da disciplina Educação Moral e Cívica no currículo, o dever sempre maior que o direito no exercício da cidadania constituíam-se num conjunto de práticas que marcou o cotidiano das escolas nesse período.

Para a presente análise, buscamos dados sobre a referida Instituição Educativos nos núcleos de documentação (CDR/MS e NDHIR/MT), onde estão reunidos os documentos oficiais, jornais da época e relatórios oriundos da Diretoria Geral da Instrução Pública de 
Mato Grosso. Recorremos também aos materiais históricos reunidos no arquivo da escola e nos acervos privados fornecidos por alguns moradores da cidade de Itaporã-MS. Foram também incorporados ao trabalho depoimentos orais fornecidos por sujeitos que vivenciaram o cotidiano do Grupo Escolar Antônio João Ribeiro no período escolhido para o estudo (1960-1970).

\section{A Escola Republicana}

Desde a inauguração da República do Brasil em 1889, os agentes políticos vislumbravam a construção da identidade nacional brasileira assentado no projeto de desenvolvimento socioeconômico da nação. Nas primeiras décadas do século XX, a escola passou a ser representada como principal requisito para garantir a modernização do país, cujo perfil envolvia transformações da paisagem urbana, industrialização e avanços científicos. Para tanto, a população precisava incorporar estes novos valores, assimilar comportamentos e mentalidades, vistos como padrões de modernidade. Isto significava a institucionalização da educação, tendo a escola como principal veículo capaz de concretizar esse ideal.

Nesse cenário, a escola passou a apresentar três modalidades organizacionais: escolas isoladas, escolas reunidas e grupos escolares. Segundo Pinheiro (2002), as escolas isoladas caracterizavam-se como modelos de organização escolar predominante nos períodos colonial e imperial e alcançou as primeiras décadas da República Velha (18891930). Poubel e Silva (2006) ressaltam que, apesar das críticas empreendidas por agentes públicos, a escola isolada abarcava um número expressivo de crianças em idade escolar graças ao caráter gratuito, flexibilidade concernente às matrículas e facilidade de comunicação dos pais com a escola.

O Artigo 33 do Regulamento da Instrução Pública Primária de 1927 estabelecia que para se constituísse como "Escolas Reunidas" seria necessário que fosse mantido o funcionamento de, no mínimo três classes que comportassem entre 15 e 45 de alunos. No caso de excederem ao número de 8 classes, se transformariam em Grupos Escolares.

Ainda na República Velha (1889-1930), emergiu no cenário educacional a instauração dos Grupos Escolares, criados inicialmente no Estado de São Paulo, em 1893, como proposta de reunião de escolas isoladas segundo a proximidade entre elas. Os grupos escolares foram responsáveis por um novo modelo de organização escolar no início da República, a qual reunia as principais características da escola graduada, um modelo utilizado no final do século XIX em diversos países da Europa e nos Estados Unidos para possibilitar a implantação da educação popular.

Com a expansão dos grupos escolares, as escolas isoladas passaram, de certa forma, a serem vistas como anacrônicas e em descompasso com o projeto moderno de escola. Se o projeto republicano tinha como bandeira o slogan "ordem e progresso", pautado no positivismo, era quase impossível defender modelos educacionais herdado do passado colonial e imperial, vistos pelos agentes políticos da República com insígnia do atraso, da precariedade, do ambiente malsão ou insalubre, da carência e da escassez material.

O grande entusiasmo e expectativa dos diversos segmentos da população no regime republicano ancoravam-se na possibilidade de ampliação dos direitos políticos e civis. No 
entanto, Carvalho (1987, p. 83) faz a seguinte reflexão: “as razões ideológicas [liberalismo radical] e as próprias condições do país fizeram com que as expectativas se orientassem em direções distintas e afinal se frustrassem”. Entre as frustrações destacadas por Carvalho (1997), eram sentidas principalmente no meio urbano mais populoso, com destaque para o Rio de Janeiro, onde se observou a presença de inúmeros trabalhadores carentes de direitos políticos, graças ao alto índice de migrantes estrangeiros; italianos, portugueses e japoneses, trabalhadores de distintas atividades, como jornaleiros, estivadores, ambulantes e outros com profissões não definidas.

O caráter excludente nas primeiras décadas da República afetava a população menos favorecida economicamente perpassou nas letras das cartas constitucionais brasileiras, tanto no regime imperial como nas experiências republicanas, como a de 1891, que, segundo Carvalho (1987, p. 35) "excluiu os pobres (quer pela baixa renda, quer pela falta de instrução primária) e os mendigos, as mulheres, os menores de idade, os praças de pré, os membros de ordens religiosas". As cartas constitucionais de 1937 (Estado Novo) e de 1946 não foram diferentes, pois foram mantidas as restrições políticas à participação popular, além de sérias dificuldades ao acesso à instrução pública.

\section{A Reforma da Instrução Pública de 1927}

A escolarização rural foi mencionada em três momentos da história mato-grossense durante a Primeira República (1889-1930). O primeiro momento foi nos termos da Reforma da Instrução Pública Primária de 1910, sob auspício do modelo paulista, na qual foram mantidas as diretrizes do regulamento de 1896, que defendiam critérios de laicidade, obrigatoriedade, gratuidade do ensino e uso do método intuitivo e prático.

O segundo momento foi o relatório do professor da Escola Mista de Lagunita (MATO GROSSO, 1916), de Ponta Porã, enviado ao inspetor daquele período. O relatório apresenta o detalhamento nominal das matrículas registradas até o mês de julho de 1916 e, dentre as 38 crianças matriculadas, nenhuma delas residia a menos de 4 quilômetros da Escola, sendo encontradas até mesmo aquelas cujas residências localizavam-se ainda distantes, como por exemplo, a 28, 35 e até 50 quilômetros. Assim, nenhuma das crianças que frequentava a instituição em questão o fazia por obrigatoriedade legal.

O terceiro momento foi a reforma da Instrução Pública, em 1927, quando, oficialmente deixaram de ter o nome de escolas isoladas para serem denominadas escolas rurais, de forma mais precisa e pontual, nos relatórios e mensagens a partir de 1930 (PAES, 2011). No ano de 1927, o Estado de Mato Grosso contava com 11 Grupos Escolares instalados em todo o seu território, sendo dois na capital e um em cada uma das seguintes cidades do interior e Sul do Estado: Poconé, Cáceres, Rosário-Oeste, Corumbá, Miranda, Aquidauana, Campo Grande, Três Lagoas e Ponta Porã. A despeito dos propósitos modernizadores do ideal republicano centrados nos interesses das elites urbanas, Souza (2010, p. 155) salienta a permanência das escolas isoladas no cenário educacional brasileiro "[as escolas isoladas] sobreviveram à sombra dos grupos escolares, nas cidades, nos bairros e no campo... nelas continuou predominando a carência de tudo: materiais escolares, livros, cadernos, salas apropriadas e salários para professores". 
Entre os anos de 1920 e 1927, as escolas isoladas apareceram com mais frequência na documentação regional, antes da Reforma da Instrução Pública de 1927, portanto. Silva (2012) dá conta de que o Regulamento da Instrução Pública Primária de 1927 acabou instituindo a escola isolada rural como modalidade que se manteve até a consolidação dos ideais escolanovistas, em 1945. O referido Regulamento alterou o cenário educacional da zona rural. Nesse Regulamento, a escola isolada rural foi desmembrada em "escolas isoladas urbanas, escolas isoladas distritais e escolas isoladas rurais" (SILVA, 2012, p. 48).

De acordo com Silva e Sá (2012), o Regulamento da Instrução Pública de 1927 classificava as escolas isoladas rurais, urbanas, reunidas e noturnas a partir de critérios quanto à localização e classificação por disponibilidade de prédios, e conforme demandas escolares (REGULAMENTO DA INSTRUÇÃO PÚBLICA, 1927).

Ainda que os discursos oficiais apresentassem preocupações sobre a escola primária rural, era bem visível, no final da Primeira República, o processo de superação das escolas isoladas rurais. Em 1930, o governador do Estado, Dr. Anníbal Toledo apontava a precariedade da escola primária rural (MATO GROSSO, 1930, p. 42). Embora as escolas isoladas rurais funcionassem com inúmeras dificuldades e precariedades, não raro, elas trouxeram contribuições para o processo de escolarização de crianças, sobretudo aquelas que moravam mais distantes das áreas urbanas. A escola isolada rural era o principal caminho de acesso ao ensino primário.

Ao acusar a ineficiência das escolas rurais, o governador do Estado supramencionado apontava para a necessidade de ampliação numérica de novos Grupos Escolares e Escolas Isoladas, sobretudo nos lugares com mais carências de espaços educativos de qualidade. Entre os anos de 1912 e 1956 foram criados aproximadamente 25 Grupos Escolares, sendo 16 localizados no atual Estado do Mato Grosso do Sul, dos quais destaquei apenas 11 no quadro a seguir:

Tabela 1 - Grupos Escolares no sul de Mato Grosso 1939-1955.

\section{Nome}

GE Amambaí General Mallan

GE de Herculânea

GE João Fernandes

GE José Garcia Leal

GE Felipe de Brum

GE Joaquim Murtinho

GE do Vale Sidrolândia

GE Antônio João Ribeiro

GE Tenente Aviador Antônio João

GE Vespasiano Martins

GE Nicolau Fragelli

\section{Cidade}

$$
\text { Campo Grande }
$$

Herculânea (Coxim)

Maracajú

Paranaíba

Amambaí

Dourados

Sidrolândia

Itaporã

Caarapó

Campo Grande

Campo Grande
Ano ou Década

1939

1945-1947

1950

1950

1950

1953

1954

1955

1955

Fonte: Mensagem de Presidente de Estado dos anos de 1939-1945; 1950 1956. 
Não podemos negar que a inauguração da República trouxe a crença de que a educação pública poderia ser o caminho para a construção da identidade nacional e, nesse sentido, trouxe também a convicção no poder redentor da educação, conforme observou Rosa Fátima de Souza (1998). Entre os anos de 1910 e 1956 foram criados, portanto, aproximadamente 26 Grupos Escolares, sendo 16 localizados no sul do estado (Quadro 2).

Tabela 2 - Distribuição dos Grupos Escolares em Mato Grosso (1910-1953).

\begin{tabular}{|c|c|c|}
\hline Ueta L - Disuriour & UIOSSO $(1910-19 J 3)$ & \\
\hline Grupos Escolares & Local & Ano \\
\hline Escola Modelo Barão de Melgaço & Cuiabá & 1910 \\
\hline GE Senador Azeredo & Cuiabá & 1910 \\
\hline GE Joaquim Murtinho & Campo Grande & 1912 \\
\hline GE Caetano de Albuquerque & Poconé & 1912 \\
\hline GE Presidente Marquez & Rosário do Oeste & 1912 \\
\hline GE Esperidião Marques & Cáceres & 1921 \\
\hline GE Affonso Penna & Três Lagoas & 1922 \\
\hline GE Luiz de Albuquerque & Corumbá & 1924 \\
\hline GE Antônio Correa & Aquidauana & 1924 \\
\hline GE Caetano Pinto & Miranda & 1924 \\
\hline GE Mendes Gonçalves & Ponta Porá & 1927 \\
\hline GE Isaac Povoas & Cuiabá & 1930 \\
\hline GE Américo Brasil & Santo Antônio do Rio Abaixo & 1930 \\
\hline GE Alzira de Lacerda Magalhães & Santo Antônio do Rio Abaixo & 1930 \\
\hline GE Leônidas de Matos & Santo Antônio do Rio Abaixo & 1930 \\
\hline GE de Amambaí General Mallan & Campo Grande & 1939 \\
\hline GE de Herculânea & Herculânea (Coxim) & 1940 \\
\hline GE João Fernandes & Maracajú & 1940 \\
\hline GE José Garcia Leal & Paranaíba (1945-1947) & 1940 \\
\hline GE Felipe de Brum & Amambaí & 1950 \\
\hline GE Joaquim Murtinho & Dourados & 1950 \\
\hline GE do Vale Sidrolândia & Sidrolândia & 1950 \\
\hline GE Antonio João Ribeiro & Itaporã & 1953 \\
\hline GE Tenente Aviador Antônio João & Caarapó & 1954 \\
\hline GE Vespasiano Martins & Campo Grande & 1955 \\
\hline GE Nicolau Fragelli & Campo Grande & 1955 \\
\hline
\end{tabular}


Fonte: Organização Rodelini (2017) $)^{2}$.

A experiência pautada nos Grupos Escolares e nas Escolas Isoladas instaladas nos perímetros urbanos das cidades e vilas revelou-se mais eficiente que as das escolas rurais, consideradas por muitos agentes políticos como ineficiente e de investimento oneroso. Em virtude da ineficiência das Escolas Isoladas Rurais, os presidentes do estado de Mato Grosso tinham muita resistência em prover de novos professores para aquelas escolas que ficassem sem docente (MATO GROSSO, 1930). Apesar dessas restrições às escolas isoladas rurais, grande parte das pequenas cidades, vilas e povoados mantiveram vivas essa modalidade escolar.

Esse princípio nascido na aurora republicana orientou por muitos anos o sistema educacional brasileiro. Muitos povoados, vilas, distritos e cidades surgiram no sul de Mato Grosso apenas depois do esgotamento do empreendimento privado da Empresa Mate Laranjeira, na década de 1940, quando Vargas desenvolveu o projeto político da "Marcha para Oeste", o qual determinou, entre muitas ações, a criação de colônias agrícolas em Goiás e Mato Grosso.

\section{"Terra de todos os povos"}

Itaporã pertence à microrregião conhecida como Território da Grande Dourados ${ }^{3}$, território este abrange uma área de $21.329,50 \mathrm{Km}^{2}$.

Quadro 3 - Municípios formadores da Grande Dourados

\begin{tabular}{|c|c|c|}
\hline Município & Ano de criação & $\begin{array}{c}\text { Distância aproximada em relação a } \\
\text { Campo Grande (Km) }\end{array}$ \\
\hline Dourados & $20 / 12 / 1925$ & 235 \\
$26 / 9 / 1929$ & 150 \\
Rio Brilhante & $10 / 12 / 1953$ & 231 \\
Itaporã & $20 / 12 / 1958$ & 264 \\
Caarapó & $11 / 11 / 1963$ & 263 \\
Glória de Dourados & $11 / 12 / 1963$ & 248 \\
Jateí & $11 / 121963$ & 232 \\
Fátima do Sul & $13 / 5 / 1976$ & 245 \\
Deodápolis & $12 / 5 / 1980$ & 185 \\
Douradina & &
\end{tabular}

\footnotetext{
${ }^{3}$ As informações de conteúdo foram organizadas por meio da Mensagem de Presidente de Estado de Mato Grosso, dos anos de 1912, 1924,1927; Mensagem de Presidente de Estado dos anos de 1924, 1945, 1950, 1955.

${ }^{3}$ Cf. Plano Territorial de Desenvolvimento Rural Sustentável - Território Rural da Grande Dourados - MS. Ministério do Desenvolvimento Agrário. Fundação Cândido Rondon, 2006. Disponível em: <http://sit.mda.gov.br/download/ptdrs/ptdrs_territorio047.pdf>.. Acesso em: 21 fev 2015.
} 


\begin{tabular}{|c|c|c|} 
Vicentina & $20 / 6 / 1987$ & 241 \\
Jutí & $14 / 12 / 1987$ & 302 \\
Nova Alvorada do Sul & $18 / 12 / 1991$ & 107 \\
\hline
\end{tabular}

Fonte: Secretaria de Estado de Planejamento e de Ciência e Tecnologia- Seplanct/MS, 2005.

O município de Dourados tem área total de 4.086.387 $\mathrm{Km}^{2}$, na qual se assenta uma população aproximada de 198.421 habitantes. Seu território data do final do século XIX e revela um município localizado na parte interna do país, cuja extensa faixa fronteiriça com o Paraguai abrigou e abriga múltiplos indivíduos e instituições. Quanto ao aspecto econômico, em relevante estudo dedicado à erva-mate, Daniel (2009) ressaltou que, na década de 1920, o Brasil, graças aos ervais nativos do sul de Mato Grosso, já era considerado o maior exportador do referido produto para a Argentina. À época, havia se consolidado a expansão e o fortalecimento da Companhia Mate Laranjeira a ponto de tornar-se a maior detentora de extração na região sulina de Mato Grosso, "responsável pela fundação de cidades, vilas e até escolas" (DANIEL, 2009, p. 84.). Conforme Daniel (2009), esta atividade se fez à custa da exploração da mão de obra disponível na região, envolvendo homens, mulheres e crianças.

Com o advento do Estado Novo (1937-1945), o projeto político de Vargas estimulou a diversificação da agricultura, embora tivesse mantido a grande propriedade. $\mathrm{O}$ signo "trabalho e colonização" orientaram o projeto "Marcha para o Oeste", cuja essência distribuía terras para trabalhadores nacionais e estrangeiros que tivesse alguma experiência agrária. Sob o discurso de ocupar os "espaços vazios", o Estado buscava a espaços já ocupados por índios ou populações sertanejas tradicionais (ribeirinhos, e outros tipos humanos do interior brasileiro). Com este projeto político-ideológico, objetivava-se colonizar e nacionalizar as fronteiras pela ação de colonos sob a tutela do Estado, que assumia, a partir de então, a coordenação que iria nortear a vida socioeconômica do país. Nessa direção, a marcha foi interpretada politicamente como "fator de unidade nacional, defesa, exploração e povoamento das fronteiras", com destaque para o centro oeste do país, conforme observou Saboya (1999, p. 51).

Os escritos mais antigos sobre essa região revelam a imagem de uma sociedade multicultural, caracterizada por uma identidade homogênea, de sentimento comum de amor à terra. Forjou-se através desse discurso uma visão de que a região, embora constituída por diferentes culturas (povos originários, migrantes sulinos, paulistas e mineiros, entre outros), dotava-se de expressiva convivência harmônica, sem problemas identitários e sociais.

De acordo com Arakaki (2003) a "Marcha para o Oeste" traduziu-se como ícone do sucesso da política de ocupação ordenada durante a Era Vargas (1930-1945), segundo modelo de seu projeto de colonização. Desde o surgimento da Colônia Agrícola Nacional de Dourados (CAND), em outubro de 1943, pelo Decreto-lei $\mathrm{n}^{\circ}$. 5.941, a região despontouse como roteiro político nacional. No caso de Dourados, esse contexto ensejou significativo enfraquecimento da área de influência Companhia Privada Mate Laranjeira ${ }^{4}$ e, consequente desagregação dos contratos de arrendamento de terras. Ao criar o Território

\footnotetext{
${ }^{4}$ A Companhia Matte Larangeira foi uma empresa que surgiu de uma concessão imperial ao comerciante Thomaz Larangeira, por serviços prestados na Guerra do Paraguai. Atuou na exploração de erva-mate no sul do Mato Grosso
} 
de Ponta Porã (1943), o Governo decretou a falência da Companhia Mate Laranjeira que, até então, arrendava cerca de um milhão de hectares de terra e, por mais de cinquenta anos, deteve poder econômico na região. O reconhecimento legal da CAND se deu em 20 de julho de 1948, quando houve a efetivação de sua demarcação pelo Governo Federal, por meio do Decreto-lei número 87.

Durante os anos de 1950 a concentração de terra era considerada por determinados agentes políticos como obstáculo para o desenvolvimento industrial brasileiro. No entanto, outros ramos de produção, assentados em incentivos fiscais e reformas de base, mantiveram o controle das antigas estruturas agrárias mediante a apropriação de grandes porções de terras do Norte, Nordeste e Centro Oeste.

As características básicas do espaço sul mato-grossense expressou nos seguintes fatores: na vastidão territorial; na complexa situação fronteiriça entre os países do Brasil e da República do Paraguai; nas grandes distâncias existentes entre a região e os principais centros brasileiros; na precariedade das vias de comunicação; no pequeno segmento migrante "não indígena" em meio à extensa população indígena; na dispersa e crescente estrutura fundiária marcada pela grande propriedade (QUEIROZ, 2003).

No que concerne à identidade cultural, a "Grande Dourados" repartiu sua identidade de fronteira com o Paraguai tanto com culturas oriundas dos mais distintos estados brasileiros, como com a cultura herdada do norte mato-grossense, ou com aquelas de costumes adquiridos das populações de outros países vizinhos.

Lilia Galetti ilumina que nas representações deste território, combinavam-se o sentimento de "ufanismo" e "pessimismo" ao mesmo tempo, desenhando-se, assim, o mapa de um país cujos atributos naturais que, ora favoreciam a construção, no futuro, de grande e poderosa nação, ora pareciam condená-lo a submergir na "barbárie". O enfrentamento das dificuldades regionais seria o caminho para se alcançar "o progresso" e a "civilização" num território gigantesco, cuja maior parte era ainda praticamente despovoada e desconhecida. (GALETTI, 1995).

O "mito da barbárie" reproduziu uma visão pessimista do sertão, visto como lugar de "atraso", e onde a natureza, praticamente intocada pela "civilização", submetia suas forças primitivas a uma população composta de índios (vista como obstáculo ao progresso regional) e de mestiços (tidos como indolentes). Segundo Galetti (1995, p. 50), esse imaginário regional foi amplamente divulgado através dos relatos e memórias, traduzidas nas representações de uma sociedade cotidianamente em conflito e, por isso, constantemente armada. Estas representações procuravam explicar o elevado índice de criminalidade; de contrabando; das ações voltadas à corrupção e aos famosos currais eleitorais presentes nos primeiros anos da República.

Foi nesse contexto que, por iniciativa do Governo Federal, emergiu o CAND, que veio para estimular o deslocamento de trabalhadores gaúchos, nordestinos, mineiros, paulistas, catarinenses e paranaenses além de imigrantes japoneses, atraídos pela intensa propaganda de terras baratas ou doadas, caracterizadas por pequenos lotes (de 25 a 30 hectares) destinados a atividades agrícolas. A partir de então, inúmeras famílias de 
migrantes assentaram-se em Dourados, num movimento característico de expansão das "frentes pioneiras"5 no final da década de 1940.

Outro fator relevante para o desenvolvimento da região foi a inauguração da estação de Itaum da Ferrovia Noroeste do Brasil, no ano de 1949, ligação ferroviária que facilitou sobremaneira a migração de paulistas e paranaenses, em decorrência do rápido processo de expansão agrícola. A ideia de Vargas era agregar a participação da sociedade nos distintos setores da economia, sobretudo no desenvolvimento da forma de exploração da terra. Desde então, a educação passou a ser contemplada nos projetos políticos dos municípios brasileiros.

\section{Itaporã e sul de Mato Grosso: “O futuro estava lá"}

O título deste tópico é de autoria do memorialista pernambucano Aurenô Arnaldo Cordeiro, que migrou com sua esposa para a região de Dourados em 1951. Cordeiro percorreu um caminho difícil, pois, segundo ele, no trajeto de Campo Grande para Dourados enfrentou com sua família muitas tropeços materiais: "[...] em estrada de chão com muitas trepidações, buracos, atoleiros, passagem de rios sem pontes, enfim, uma grande aventura que findou por volta das cinco horas da tarde, do mesmo dia de viagem com a nossa chegada ao destino" (CORDEIRO, 2010, p. 25).

A região escolhida por Aurenô Arnaldo Cordeiro para morar contava com um antigo projeto de ocupação que remontava aos anos 1920, expresso na criação da Colônia Agrícola Municipal de Dourados (CMD). Tratava-se de uma área de 50.000 hectares de terras compreendidas entre o rio Brilhante e Panambi, no município de Ponta Porã. Essas terras tinham sido reservadas para a colonização desde 1923, através do Decreto $\mathrm{n}^{\circ}$ 616, assinado pelo presidente do Estado, Pedro Celestino Corrêa da Costa (FERREIRA, 1958). Segundo Carli (2008), a área foi reduzida, em 1932, para 30.000 hectares.

Por volta de 1946, o então prefeito de Dourados, João Augusto Capilé Junior, resolveu explorar as terras reservadas para avançar com a colonização e definiu uma pequena área com baixa vegetação para ser a sede da futura colônia. Em 1948, assumiu a Prefeitura de Dourados o Sr. Antônio de Carvalho, que continuou o projeto colonizador iniciado por Capilé Junior.

Ao chegar ao Patrimônio Novo, São José da Boa Esperança e Panambi como era chamada a cidade de Itaporã, antes de se tornar município, cada família marcava seu lote. Segundo o relato memorialístico de Dona Izabel Moura (CORDEIRO, 2010), uma das integrantes das primeiras famílias a chegar à referida região, os colonos encontraram uma aldeia de índios e dois moradores na localidade, mas não souberam informar quem eram eles.

\footnotetext{
5 "Frentes pioneiras" é uma constante cultural e política da colonização brasileira: os projetos de colonização privada estão todos concentrados em torno de um núcleo urbano principal, cujo desenvolvimento é freqüentemente assegurado pela distribuição de um lote urbano para cada aquisição de um lote rural (PASSOS, 2006).
} 
Após a demarcação dos lotes, os novos ocupantes seguiram a pé até a cidade de Dourados (então sede do Município) onde requereram a posse de seus lotes. Assim, no ano de 1944 chegaram sete famílias à região onde hoje é o Município de Itaporã, instalando-se próximo ao Córrego Canhadão. Eram eles: Sr. Rogério Moura e $\mathrm{Sr}^{\mathrm{a}}$ Izabel Moura, Sr. Inácio Félix e Sr ${ }^{\mathrm{a}}$ Joaquina Moura, Sr. Miguel Moura e $\mathrm{Sr}^{\mathrm{a}}$ Maria Carolina Gimenez Moura , Sr. Antonio Camilo Diniz e Sra Maria Lucinda Diniz, Sr. Januário Rodrigues e Sr ${ }^{a}$ Odília, Sr. Benedito Pereira e Sra Maria Camilo, Sr. Joaquim Rodrigues e Sr ${ }^{a}$ Brolínia Camilo.

Com a chegada de um maior número de colonos oriundos de São Paulo e Paraná, a prefeitura de Dourados nomeou o Sr. Inácio Félix como fiscal e coordenador da distribuição de lotes para os colonos que encontravam dificuldades pela falta de estradas entre o Patrimônio Novo (Itaporã) e Dourados. Os primeiros moradores chegavam com suas mudanças em carros de bois ou, no lombo de burros ou cavalos, ou, mesmo a pé. Os homens iam à frente abrindo caminho na mata com foices e machados, e logo atrás vinham mulheres, crianças e agregados.

De acordo com Aurenô Cordeiro (2010), em 1950 foi construída a primeira igreja católica, no sistema de mutirões, com um pequeno salão e uma sacristia. O espaço era destinado também para uma escola de corte e costura coordenada pelas irmãs missionárias. Ressalte-se que o corte e costura era um dos poucos ofícios que as mulheres podiam exercer caso contraísse matrimonio. O imaginário popular, oriundo do modelo patriarcal de família, entendia que o ofício de costureira não interferia nas práticas do lar, tarefa exclusivamente delegada à mulher.

Aurenô Cordeiro chegou ao atual município de Itaporã no ano de 1951, localidade situada no sul do antigo estado de Mato Grosso, na antiga Colônia Municipal de Dourados (1946 e 1953), conforme já referimos. Diante do fenômeno migratório ocorrido a partir de 1946, a Prefeitura do município de Dourados decidiu criar uma base para a colonização orientada, tornando-se espaço povoado por "não índios”, já em 1948.

A ocupação da região de Itaporã deu-se em virtude da propaganda ligada à fertilidade do solo para o plantio do café. O processo de migração rural intensificou o movimento de famílias oriundas de distintos pontos do país, para a formação da sociedade sulina de Mato Grosso. Em distintos aspectos esse processo migratório alterou o aspecto geohistórico do espaço e promoveu a diversidade da cultural pois traziam consigo seu capital cultural, traduzidos nos objetos pessoais, nos instrumentos de trabalho, na culinária, nas crenças e costumes.

À época, as escolas eram erguidas com madeira, material abundante na região, utilizado frequentemente para fins estruturais e de sustentação de construções, e também para construção de mobiliários, como bancos, mesas e carteiras escolares. Na falta do profissional para exercer a função docente, buscava-se alguém na comunidade com certo grau de escolaridade para atuar no ensino, ainda que fossem leigos. Segundo relatos orais, as famílias que chegaram a Itaporã no ano de 1946 do século XX iniciaram ações ou mobilizações com objetivo de construir estabelecimentos para atender as necessidades de seus próprios filhos..

Com a chegada dos migrantes de diversas regiões do país a Itaporã, o município recebeu uma nova demanda de crianças em idade escolar intensificando a necessidade de investimento na escolarização da infância. Assim, foi criado através do Decreto $\mathrm{n}^{\circ} 1.927$ de 14 de julho de 1954, as escolas Reunidas de Itaporã. Posteriormente, o decreto n $^{\circ} 2.197$ de 
17 de agosto de 1955 transformou as Escolas Reunidas da cidade de Itaporã em Grupo Escolar com a denominação de Antonio João Ribeiro, em homenagem ao grande herói da colônia militar de Dourados, (1823-1864) ${ }^{6}$. No primeiro ano de seu funcionamento, assumiu a direção da escola o professor Marcelino Lopes de Oliveira.

De acordo com as Crônicas da Escola Santo Antônio (1958-2002), realizadas por missionárias franciscanas, quando estas chegaram à cidade de Itaporã, em 1958, havia duas escolas na região, uma delas era rural mista e estava localizada do lado do cemitério, e a outra era o Grupo Escolar (G.E.) Antônio João Ribeiro. Como o número de alunos do GE era baixo, contando apenas com 70 alunos, as irmãs encabeçaram um mutirão junto à comunidade para que as crianças fossem matriculadas. No ano seguinte, o número de aluno de alunos matriculados no GE cresceu de 70 para 300, espelhando a carência de escolas, de informações e o crescimento populacional da cidade

A procura cresceu a ponto de, em 1968, as 4 salas de aula não atenderem mais a demanda de crianças e adolescentes em idade escolar. Desse modo, as irmãs, a comunidade e os políticos pleitearam junto ao governo do Estado a construção de mais duas salas de aula; contou, nesse momento, com a participação do deputado Weimar Gonçalves Torres, na época, proprietário do jornal: "O Progresso". Na década de 1950, as professoras eram nomeadas através de indicação política do prefeito de Itaporã, fato que causava sério problema administrativo no GE Antonio João Ribeiro, pois a cada nova eleição o grupo político vencedor exonerava as professoras vinculadas ao partido adversário e eram nomeadas outras pelo partido vencedor.

No sul de Mato Grosso, a necessidade de acelerar a educação enfrentava limites ligados, conforme referido, à carência de professor habilitado, tanto no campo como na cidade, isso explicava o fato de haver constantes apelos a pessoas não habilitadas para exercer o ofício de ensinar a ler, escrever, contar ou transmitir algumas regras para o "bom convívio" social e sobretudo, noções de higiene.

De acordo com informações contidas no Livro de Registro do Grupo Escolar Antonio João Ribeiro (1955-1966), em 1967 chegou ao GE a primeira professora normalista, Conceição Nonato, contratada de acordo com o que preconizava o artigo $\mathrm{n}^{\circ} 39$ do Regulamento de 1927.

O GE Antônio João Ribeiro foi à primeira escola de Itaporã construída exclusivamente para ser "escola de verdade", com localização privilegiada, no centro da cidade, com fácil acesso; representava os interesses de uma sociedade pautada nos ideais de cidadania, civismo, higienização e progresso.

Tornou-se, a partir do condão nacionalista da época, a tradicional prática do culto às datas cívicas na cidade de Itaporã, que se faziam por meio de desfiles e outras festividades. Além de recordarem fatos heroicos da história brasileira, esses eventos serviam para representar "civismo e o amor à pátria". Souza (1998) lembra que ao transformar as datas cívicas em atividades escolares.

\footnotetext{
${ }^{6}$ Antônio João Ribeiro, nasceu em 1823 / Mato Grosso. Em 1845 se tornou $1^{\circ}$ Sargento. Em 1860 chegou ao posto de. $1^{\circ}$ tenente. Antônio João foi morto durante a batalha, na Colônia Militar de Dourados em 29 de dezembro de 1864, instituído "Patrono do quadro auxiliar de oficiais" (Dec. No 85.097, de 29 de agosto de 1980).

${ }^{7}$ Uso o termo "Escolas de Verdade" com base em Tyack e Cuban (1999).
} 
No ano de 1973, assumiu a direção do GE o professor Matheus Favaretto Cortes, que permaneceu na direção até o ano de 1980. Em 7 de junho de 1974, o GE Antonio João Ribeiro foi elevado ao nível de $1^{\circ}$ grau, atual Ensino Fundamental, pelo Decreto $\mathrm{N}^{\mathrm{o}}$ 2028/74, passando a ser denominada de: Escola Estadual de $1^{\circ}$ grau Antonio João Ribeiro.

De acordo com a ata do dia 27 de fevereiro de 1969, O Grupo Escolar passava por reforma, assim, as salas de aulas funcionaram no salão paroquial, no clube social, na casa das irmãs em regime de 3 turnos, sendo o primeiro turno das 7:00 às 10:30, o segundo turno das 10:30 às 13:30, e o terceiro turno das 13:30 às 17:30. Não há ata referente à distribuição de classes e turnos aos professores no ano de 1970, 1971 e 1972.

O exame do Livro Ata do Grupo Escolar Antônio João Ribeiro (1958 a 1974) revelou que o exercício da função do magistério foi exercido, em sua grande maioria, pelo sexo feminino. As práticas docentes eram impregnadas de representações sociais sobre a identidade da mulher/mãe/professora.

De acordo com Izaira Marsura Pacco (entrevista realizada em 20/01/2014), exprofessora do Grupo Escolar Antonio João Ribeiro, a mulher perante o marido e a sociedade poderia trabalhar. Seguindo essa representação da figura da mulher, mãe de família, a única profissão que as mulheres "decentes" podiam ter era o ofício do magistério.

A escola representava a extensão do lar. Na metade do século XX, as exigências educacionais passaram a atender os interesses econômicos, estimulando debates acerca da educação. Neste sentido, surgiram reformas, entre as quais a Reforma Capanema (19421946), que representou a preocupação com o Ensino Primário e com as Escolas Normais, cujos princípios acabaram por nortear a formação de professores para o ensino primário.

Rosa Fátima (1998) assinala que a implantação dos Grupos Escolares no país atraiu pessoas para exercer a profissão docente, pois, ofereciam melhores salários e boas condições de trabalho; além disso, eram considerados escolas de qualidade e de grande prestígio social, aspecto que se estendiam ao corpo docente.

\section{CONSIDERAÇÕES FINAIS}

O Grupo Escolar Antônio João Ribeiro passou pela fase das Escolas Reunidas e alcançou a elevação a Grupo Escolar. Durante as análises, foi possível observar a relação existente entre o particular (O Grupo Escolar Antonio João Ribeiro) e o geral (A Escola Republicana Brasileira). Foi possível também evidenciar a importância desta instituição para a cidade de Itaporã. Em síntese, o GE foi uma instituição que contribuiu para a escolarização e construção cultural regional, sendo a escola a base propagadora da tão discursada modernidade difundida representantes do Estado brasileiro.

A análise sobre o Grupo permitiu visualizar os anseios dos poderes constituídos no sentido de incutir na sociedade os princípios republicanos, independente de suas particularidades. Os políticos públicos e as camadas mais abastadas da sociedade incorporavam discursos capazes de promover um projeto educacional com objetivo de trazer ao município os clarões da "modernidade" e do "progresso", princípios estes que tirariam o restante dos agentes sociais de Itaporã e da região, do analfabetismo e da 
ignorância, herança do passado colonial e imperial. O Grupo Escolar Antônio João Ribeiro representou, naquele período, o ato principal de investida política para a formação do cidadão "moderno e civilizado", a partir da difusão de princípios cívicos, morais e patrióticos, ou seja, da formação do cidadão adequado ao projeto do Estado. Em linhas gerais, é possível afirmar que o Grupo Escolar contribuiu, de maneira significativa, para a escolarização de meninos e meninas moradores do município de Itaporã entre os anos de 1953 a 1974.

\section{REFERÊNCIAS}

CARVALHO. Abdias Vilar de. Crise política e transformação do Estado brasileiro (19301945). Brasília: UNB, 1978.

CARVALHO, José Murilo de. Os Bestializados: o Rio de Janeiro e a república que não foi. Rio de Janeiro: Companhia das Letras, 1987.

CERTEAU, Michel de. A escrita da história. Rio de Janeiro: Forense Universitária, 1970.

CHARTIER, Roger. O mundo como representação. In: CHARTIER, Roger. À beira da falésia: a história entre incertezas e inquietude. Porto Alegre: Ed. Universidade/UFRGS, 2002.

CORDEIRO, Aurenô Arnaldo. A vida e os sonhos de um nordestino parente de todos. Campo Grande: Centro gráfico Ruy Barbosa, 2010.

. Depoimento (mar. 2014). Entrevistadora: Claudiani Rodelini. Itaporã - MS,

2010.

FERREIRA, Jurandyr Pires. Enciclopédia dos Municípios Brasileiros. Rio de Janeiro: IBGE, 1958. LIVRO DE CRÔNICAS DA ESCOLA SANTO ANTÔNIO, Itaporã, 19582002.

LIVRO DE REGISTROS de alunos do Grupo escolar Antonio João Ribeiro - 1955-1959.

LIVRO ATA DAS REUNIÕES do Grupo Escolar Antonio João Ribeiro, 1958-1976.

MATO GROSSO. Regulamento da Instrução Primária do Estado de Mato Grosso. Coleção de Leis e Decretos. Cuiabá, 1910. 
MATO GROSSO. Regulamento da Instrução Pública, 1927. Arquivo Público de Mato Grosso, 1927.

MATO GROSSO. Decreto Estadual 1.927 de 1954. Criação da Escola Reunida de Itaporã, 1954.

MEDEIROS, Joana Prado. O Eldorado de Dourados: A Colônia dos Baianos e Colônia Café Porã - 1950 a 1960. Dourados: CEUD/UFMS, 2001.

NÓVOA, António. Para o estudo sócio-histórico da gênese e desenvolvimento da profissão docente. Teoria e \& Educação. Porto Alegre, n. 4, 1991, p. 109-158.

OLIVEIRA, Carlos Edinei de. Migração e escolarização: história de instituições escolares de Tangará da Serra - Mato Grosso - Brasil (1964 -1976). Tese Doutorado em Educação, Faculdade de Educação, Universidade Federal de Uberlândia, Uberlândia, 2009.

PACCO, M. Izaira. Depoimento (mar. 2014). Entrevistadora: Claudiani Rodelini. Itaporã MS, 2014.

PAES, Ademilson Batista. A escola primária rural em Mato Grosso no período republicano. Tese de Doutorado em Educação, Faculdade de Ciências e Letras, Universidade Estadual Paulista, Araraquara, 2011.

PINHEIRO, Antonio Carlos Ferreira. Da era das cadeiras isoladas à era dos grupos escolares na Paraíba. Campinas, SP: Autores Associados, São Paulo: Universidade São Francisco, 2002.

QUEIROZ, Paulo Roberto Cimó. Divisionismo e "identidade” mato-grossense e sul-matogrossense: um breve ensaio. Dourados: UFGD, 2003.

SILVA, E. F. S. P. Revista Brasileira de História da Educação. 2012. Disponível em: <rbhe.sbhe.org.br>. Acesso em: <13 Fev. 2015>.

SILVA, Marineide de Oliveira; SÁ, Elizabeth Figueiredo de. As escolas rurais de acordo com a legislação mato-grossense. Cuiabá: UFMT, 2012.

SOUZA, Rosa F. Templos de Civilização: A Implantação da Escola Primária Graduada no Estado de São Paulo (1890-1910). São Paulo: Fundação Editora UNESP, 1998. 
. Alicerces da Pátria: escola primária e cultura escolar no estado de São Paulo (1890-1976). Tese Livre-Docência, Faculdade de Ciências e Letras, Universidade Estadual Paulista, Araraquara, 2006.

Aprovado: 20/02/2017

Recebido: 30/03/2017 